\title{
ASPECTOS PRODUTIVOS E SANITÁRIOS DE VACAS MESTIÇAS LEITEIRAS TRATADAS COM PRODUTOS HOMEOPÁTICOS
}

\author{
R.D. Signoretti ${ }^{1}$, C.J. Veríssimo ${ }^{2}$, F.H.M. de Souza ${ }^{3}$, E.M. de Oliveira ${ }^{3}$, V. Dib ${ }^{3}$ \\ ${ }^{1}$ Polo Apta da Alta Mogiana, Av. Rui Barbosa, s/no, CEP 14770-000, Colina, SP, Brasil. E-mail: signoretti@ \\ apta.sp.gov.br
}

\section{RESUMO}

\begin{abstract}
Nos dias de hoje, a população mundial exige o consumo de alimentos de qualidade, sem resíduos de produtos químicos. Desempenho (produção e qualidade do leite, peso e condição corporal) e sanidade (mastite e infestação por ecto e endoparasitas) foram acompanhados em oito vacas leiteiras mestiças de um rebanho de 40 (20\%), que recebeu diariamente produtos homeopáticos comerciais no concentrado para o controle de endo e ectoparasitas e mastite. No período de nove meses, que correspondeu a toda uma lactação, não houve necessidade de medicar com produtos alopáticos nenhuma vaca do rebanho, o que demonstrou ser possível criar vacas leiteiras mestiças não utilizando produtos químicos para o combate a parasitas (carrapato, mosca-do-chifre e verminose), ou antibióticos para o controle de mastite, e sem interferir na produtividade dos animais.
\end{abstract}

PALAVRAS-CHAVE: Bovinos, carrapato, desempenho, homeopatia, mastite, parasita.

\section{ABSTRACT}

PRODUCTIVE AND SANITARY ASPECTS OF CROSSBRED MILKING COWS RECEIVING HOMEOPATHIC PRODUCTS. Nowadays the world population demands food of good quality, without any residues from chemical products. Eight cows from a herd of 40, which were consuming commercial homeopathic medicines at the daily concentration for control of endo-and ectoparasites, were monitored in terms of their performance (production and quality of milk, body score and body weight) and sanitary aspects (parasites infestation and mastitis) during the lactation period. It was not necessary to give any allopathic (conventional) medicines to control mastitis or parasites (ticks, horn-fly, verminosis) in any cow of the herd during the nine months of the lactation period. The results showed that it is possible to produce milk without using chemical products, and not interfering in the productivity of the crossbred animals.

KEY WORDS: Cattle, performance, homeopathy, mastitis, parasites, tick.

\section{INTRODUÇÃO}

O interesse dos produtores pela agricultura orgânica tem aumentado, em um mundo globalizado que valoriza a qualidade dos alimentos consumidos. O Brasil ocupa atualmente a segunda posição na América Latina em termos de área manejada organicamente, e estima-se que a produção orgânica no país esteja entre 120 e 200 milhões de dólares (SiLva et al., 2005).

Cooperativas têm estimulado o uso de produtos homeopáticos por parte de produtores de leite, inclusive remunerando melhor o leite produzido por vacas homeopatizadas. Dados apresentados por Mendonça (2001) revelou que nas fazendas onde houve a utilização de medicamentos homeopáticos, além dos produtores receberem uma bonificação de $1 \%$ no preço final do leite, houve menor infestação por parasitas (carrapato, mosca-do-chifre, berne) e moscas domésticas, e a qualidade do leite aumentou (menor contagem de células somáticas e casos de mastite).

Écada vez maior o uso de produtos homeopáticos e fitoterápicos por parte de pequenos produtores do sul do Brasil, que têm utilizado esses produtos alternativos por serem muito mais econômicos, diminuindo os custos de produção e remunerando melhor o produto final (BERTOLLO, 2002).

O uso de medicamentos homeopáticos na ração ou sal mineral pode atuar sobre o bem-estar dos animais, reduzindo o estresse, por sua aplicação menos aversiva e seu efeito terapêutico (HONORATO, 2006).

${ }^{2}$ Instituto de Zootecnia, Centro de Pesquisa em Zootecnia Diversificada, Nova Odessa, SP, Brasil.

${ }^{3}$ Centro Universitário da Fundação Educacional de Barretos, Barretos, SP, Brasil. 
Ectoparasitas, tais como o carrapato-do-boi [Riphicephalus (Boophilus) microplus] e a mosca-dochifre (Haematobia irritans), geralmente são controlados por produtos químicos; no entanto, esse controle vem sendo cada vez mais problemático, em função da resistência genética que esses parasitas têm adquirido em relação aos antiparasitários que estão no mercado (Furlong et al., 2007; BARROS, 2004). Felizmente, os bovinos possuem defesas naturais a esses parasitas, especialmente os zebuínos (Bos indicus) e seus mestiços. Veríssimo (1993) relatou que os prejuízos advindos de uma infestação do carrapato-do-boi podem ir da morte do animal a nenhum prejuízo, dependendo do genótipo $B$.indicus do animal: quanto maior, mais resistente, e menor o prejuízo causado por esse carrapato.

A mastite é responsável por grandes prejuízos na pecuária leiteira de todo o mundo, e já são vários os trabalhos científicos que demonstram ser eficaz o tratamento homeopático tanto no tratamento das mastites clínicas (Almeida et al., 2005a; SANTOS; GRIEBELER, 2006), como das subclínicas (AlmeIDa et al., 2005b; MARTins et al., 2007; BARZON et al., 2008; TELLES et al., 2008) e, além disso, é muito mais econômico (SANTOS; GRIEBELER, 2006).

A homeopatia, concebida no século XVIII pelo médico alemão Samuel Hahnemann, é baseada no uso de medicamentos oriundos dos reinos mineral, vegetal ou animal, diluídos em diluições decimais ou centesimais (em água ou álcool de cereais ou substância inerte) e dinamizados (agitados vigorosamente a cada diluição); quando ministrados a indivíduos sãos, esses medicamentos, diluídos e dinamizados, provocam sintomas semelhantes a determinadas doenças. Quando esses medicamentos são ministrados a pessoas doentes, que apresentam os mesmos sintomas que o medicamento causa em pessoas sadias, produz-se um estímulo das defesas orgânicas e, progressivamente, a cura (VERíssimo, 2008).

Bioterápicos e isoterápicos são produzidos a partir do agente causador da doença. Para esse fim, são utilizados organismos vivos ou secreções (ex: leite de vaca com mastite) diluídos e dinamizados, segundo a farmacopeia homeopática (SILva et al., 2008).

O uso de medicação homeopática no sal mineral ou na ração concentrada é uma alternativa ao uso de produtos químicos que, além de serem onerosos, são determinantes de contaminações ambientais, e dos indivíduos que manejam os produtos, causando problemas de saúde pública pela presença de inúmeros resíduos, e prejuízos na indústria pela interferência nos processos de fabricação de produtos lácteos e, também, nos produtos da cadeia da carne bovina. Ouso de medicamentos homeopáticos pode diminuir o número de aplicações de quimioterápicos nos animais, e reduzir a pressão de seleção sobre as cepas de carrapatos e moscas ainda susceptíveis aos tratamentos convencionais, além de ter seu uso permitido em bovinos mantidos em sistema de produção orgânica (ARENALEs et al., 2006).

Nesse sentido, buscou-se verificar o desempenho e a sanidade de um rebanho mestiço leiteiro, bem manejado nutricionalmente, que recebeu produtos homeopáticos comerciais, durante toda a lactação.

\section{MATERIAL E MÉTODOS}

\section{Local e manejo}

Conduziu-seo experimentonoSetor debovinocultura leiteira da Estação Experimental do Polo Regional da Alta Mogiana (Colina, SP), unidade da Agência Paulista de Tecnologia dos Agronegócios (APTA).

Um rebanho de 40 vacas mestiças (3/4 Holandês e $1 / 4$ Gir) recebeu produtos homeopáticos durante toda a lactação. Em 8/2/2008, oito vacas (20\%) foram selecionadas, de acordo com o nível de produção ao início da lactação, e acompanhadas quanto às infestações de carrapato, mosca-do-chifre, vermes, mastite subclínica (CMT), e variação de peso, produção e qualidade do leite, ao longo da lactação. À medida em que iam secando, esses animais não foram substituídos, de modo que em agosto eram sete animais (17,5\% do rebanho total de 40$)$; setembro, seis $(15,8 \%$ do rebanho total de 38$)$; outubro, quatro (11,4\% do rebanho total de 35$)$ e, finalmente, em 1/12, completando a observação realizada em novembro, três vacas $(8,6 \%$ do rebanho total de 35$)$ foram avaliadas quanto aos parâmetros estudados.

As vacas selecionadas ao início da fase experimental, em 8/2/2008, foram pesadas e realizou-se a avaliação inicial (avaliação 0) das infestações de carrapatos, vermes e mosca-do-chifre, antes do fornecimento do medicamento homeopático, assim como foi registrada a produção e a qualidade do leite.

As vacas foram alocadas em área experimental, de 4,2 ha, formada com a forrageira capim-tanzânia (Panicum maximum cv. Tanzânia), subdividida em 24 piquetes $\left(1.750 \mathrm{~m}^{2}\right.$ cada), que foram manejados sob o método de lotação intermitente, no período das águas, um dia de ocupação e 23 de descanso. A área, no período das águas, foi fertilizada com 150 $\mathrm{kg}$ de nitrogênio/ha.

Durante o período da seca (junho, julho, agosto, setembro e outubro de 2008), as vacas continuavam a ser manejadas sob o método de lotação intermitente, um dia de ocupação e 23 dias de descanso, e receberam diariamente silagem de cana-de-açúcar sem aditivo, à vontade.

Nas águas, as vacas receberam pasto e concentrado (para cada 3,0 L deleite um quilo de concentrado), e na seca, silagem de cana-de-açúcar e concentrado (para cada 2,5 L de leite um quilo de concentrado). 
No concentrado foram adicionados os medicamentos homeopáticos: FATOR PRÓ ${ }^{\circledR}, \mathrm{ESTRESSE}^{\circledR}$, $M \& \mathrm{P}^{\circledR}$ e $C \& M C^{\circledR}$ Arenales (na proporção de $5 \mathrm{~g} /$ animal/dia), para incremento de ganho de peso, combate ao estresse, controle de mastite e controle de parasitos, respectivamente. O concentrado foi formulado com milho moído, polpa cítrica, farelo de trigo, farelo de soja, ureia e sulfato de amônio, mistura mineral e sal comum, e foi fornecido diariamente, após as ordenhas da manhã e da tarde.

Emsuaformulação, oFATORPRÓßpossuisubstâncias extraídas dos reinos vegetal e mineral, diluídas e dinamizadas, segundo a farmacopeia homeopática, que visam melhorar a digestibilidade dos alimentos e, consequentemente, o desempenho dos animais. O FATOR ESTRESSE® contém em sua formulação substâncias extraídas do reino vegetal, diluídas e dinamizadas, com indicação para minimizar o estresse. O FATOR M\&P® contém substâncias ex-traídas do reino vegetal, diluídas e dinamizadas, comindicação para a mastite em bovinos, causada por Staphylococcus aureus, Streptococcus agalactiae, Streptococcus dysgalactiae, Streptococcus uberis e Escherichia coli. Indicado também parainfecções docascoem bovinos.OFATORC\&MC ${ }^{\circledR}$ contém os isoterápicos $R$. (Boophilus) microplus, Amblyomma cajennense, Haematobia irritans, Musca domestica, Bunostomum sp., Haemonchus contortus, Haemonchus placei, Nematodirus sp., Oesophagostomum sp. Strogyloidessp., Trichostrongylusaxei, Trichostrongylus colubriformis, Trichuris sp., Eimeria sp., Cysticercus cellulosae e Dermatobia hominis, todos preparados na $12^{a}$ diluição centesimal e dinamização (CH12). Todos os medicamentos são veiculados em sacarose e preparados de acordo com a Farmacopeia Homeopática BRASILEIRA (1997).

\section{Avaliações}

As avaliações nos oito animais selecionados foram feitas pela manhã em: 8/2/2008 (avaliação 0), 6/3 (avaliação 1), 3/4 (avaliação 2), 21/5 (avaliação 3), 26/6 (avaliação 4), 21/7 (avaliação 5), 25/8 (avaliação 6), 25/9 (avaliação 7), 28/10 (avaliação 8), 4/12 (avaliação 9). Os animais foram pesados e o escore de condição corporal foi avaliado, atribuindo-se notas de 1 (muito magra) a 5 (muito gorda). Também foram feitas avaliações de infestações naturais pelo carrapato R. (Boophilus) microplus pelo método simplificado (Veríssimo; Oliveira, 1994) e pela contagem de ínstares (Veríssimo et al., 1997b); avaliações da presença de mosca-do-chifre (H. irritans) (presença acima de 20 moscas ou ausência) e colheita de fezes para determinação do número de ovos denematoides por grama de fezes (OPG), de acordo com a técnica
deGordon eWhitlock modificada (UENO; GonÇALVES, 1998), também foram realizadas nesses dias.

O teste CMT (California Mastitis Test) (Schalm; NoORLANDER,1957) foi realizadomisturando-se $2 \mathrm{mLde}$ reagente* $2 \mathrm{~mL}$ deleite, everificando-sea intensidade de alteração da viscosidade da mistura. A produção de leite foi registrada semanalmente, e a composição e a qualidade [contagem de células somáticas (CCS) e bacteriana global (CBG)] foram mensuradas mensalmentenotanque deexpansão, conformerecomendação da Instrução Normativa 51 (BRASIL, 2002).

\section{RESULTADOS E DISCUSSÃO}

\section{Controle de ecto e endoparasitos}

Verificou-se que a infestação de carrapatos $R$. (Boophilus) microplus, tanto por adultos (fêmeas) quanto por ínstares (larvas, ninfas, machos efêmeas), diminuiu ao longo do tempo de avaliação (Figs. 2 e 3), e não foi necessário utilizar carrapaticida em nenhuma das 40 vacas do rebanho em todo o período experimental.

Quanto à avaliação das moscas-do-chifre (Fig. 4), verificou-se que nos meses de maio e junho (época da seca) todos os animais observados estavam com mais de 20 moscas, e durante a primavera (setembro a dezembro) a infestação também aumentou. $\mathrm{O}$ aumento da infestação em maio e junho pode ter sido reflexo do acúmulo de chuvas nos meses anteriores e, na primavera, devido ao início das chuvas neste período (Fig. 1). Entretanto, vale ressaltar que não houve necessidade da utilização de produtos químicos específicos para o controle dessa mosca no rebanho, durante o período de observação.

Em relação à contagem de ovos de nematoides por grama de fezes (OPG), esta, que já começou muito baixa (média de 131), diminuiu, ainda mais, ao longo do tempo, chegando a zerar nas três últimas observações (Fig. 5). O OPG de bovinos adultos é normalmente baixo, porque os animais adquirem imunidade aos helmintos gastrintestinais por volta de 18 meses de idade (BiAnCHIN; CATTO, 2008). Assim, a baixa infestação apresentada pelas vacas durante toda a lactação já era esperada. Nenhuma vaca do rebanho foi vermifugada antes ou depois do parto.

Resultados de pesquisa mostraram efeito positivo dos medicamentos homeopáticos no controle do carrapato: Veríssimo (1988) relatou a interferência positiva de um isoterápico feito com teleóginas do carrapato R. (Boophilus) microplus dinamizado na $\mathrm{CH} 6$, na forma líquida, e fornecido na água de bebida por 36 dias, para novilhos mestiços leiteiros que 
foram infestados artificialmente com 20.000 larvas do carrapato (menor número de carrapatos e menor perda de peso nos animais que receberam o produto, em relação a um grupo controle que não recebeu); ARENAles et al. (2006) atribuíram ao uso de medicamentos homeopáticos (FATOR PRÓ ${ }^{\circledast}$ e C\&MC ${ }^{\circledast}$ ) o adequado controle de ecto e endoparasitoses, e o incremento de $37,9 \%$ no ganho de peso de novilhos nelore, em relação a animais controle que receberam aplicações periódicas de produto químico à base de ivermectina; e SILVA et al. (2008) constataram que o fornecimento do fator $C \& M C^{\circledR}$ diariamente no sal mineral por um período de 12 meses foi eficaz em diminuir a infestação de carrapatos em novilhas da raça Purunã em relação ao grupo controlenão tratado. Não houve diferença significativa na infestação entre o grupo tratado com homeopatia e o grupo tratado com o produto químico à base de amitraz. MAGALHÃES NeTO et al. (2005) observaram efeito positivo do FATOR C\&MC ${ }^{\circledR}$ ministrado diariamente a vacas leiteiras no sal mineral, verificando menores infestações, e teleóginas mais leves, com menor postura, nas propriedades em que o produto homeopático era utilizado, comparado àquelas que utilizavam somente produtos químicos.

Além disso, a curva epidemiológica esperada para este carrapato no local onde foi realizado o trabalho é ascendente a partir da segunda quinzena de fevereiro, com pico no outono, queda na infestação no inverno, e aumento com as primeiras chuvas da primavera, segundo dados obtidos por VERíssimo et al. (1997a,b), o que não se observou neste trabalho.

Já SigNORETTI et al. (2008) não encontraram efeito positivo de produtos homeopáticos (FATOR PRÓ, C\&MC ${ }^{\circledast}$ e ESTRESSE ${ }^{\circledast}$ ) no desempenho e infestação por ecto e endoparasitoses de novilhos mestiços leiteiros, quando comparados a novilhos controle, sem o medicamento. Igualmente, na observação feita por estes autores, na mesma propriedade onde foi realizado este trabalho, não foi preciso aplicar carrapaticida ou vermífugo no período de oito meses a nenhum animal, nem mesmo nos do grupo controle que não recebiam o medicamento homeopático, e ambos os grupos tiveram desempenho satisfatório, embora os do grupo homeopatia tenham tido um incremento de $24 \%(\mathrm{P}=0,08)$ no ganho de peso em relação ao grupo controle.

Lemos et al. (1985), Oliveira et al. (1990) e, mais recentemente, Veríssimo et al. (2002) constataram que vacas mestiças são mais resistentes a ectoparasitas do que as holandesas. Bovinos resistentes têm capacidade de autocontrolar a população de carrapatos, uma vezque estes não conseguem completar ociclonesses animais resistentes ou, quando o fazem, as teleóginas têm menor peso e, consequentemente, põem menos ovos (Veríssimo, 1999). Além disso, o fato de não se usar produto químico no rebanho não interferiu na provável população de inimigos naturais dos parasitas, permitindo que muitos insetos, tais como aranhas, formigas, muscoides do gênero Megaselia, insetos dermápteros forficulidae ("tesourinhas"), anfíbios (sapos do gênero Bufo) e aves (anu, galinha doméstica, garça vaqueira) (VERíssimo; MACHADO, 1995), entre outros inimigos naturais do carrapato e dos outros endo e ectoparasitas desconhecidos pela pesquisa, pudessem exercer predatismo sobre os parasitas, no solo ou nos animais, contribuindo para o seu controle.

\section{Produção e composição do leite}

Os resultados relativos à produção mostram estabilidade na produção leiteira, com pequena redução observada no mês de maio (avaliação 3), e queda acentuada no último mês da observação (Fig. 6). As vacas entraram no experimento recémparidas e, como já era esperado, houve redução na produção de leite ao final da lactação. A pequena queda observada na produçãoleiteira no mês demaio foi devido, provavelmente, à diminuição na qualidade do capim que, geralmente, ocorre no outono [menor porcentagem de folhas, maior porcentagem de colmos e maior quantidade de material morto, segundo SANTOS et al. (2005)]. suplementação das vacas com volumoso (silagem de cana-de-açúcar) e maior quantidade de concentrado somente começou a ser fornecida no mês de junho.

Uma das vacas monitoradas apresentou grumos no leite no posterior esquerdo, no mês de maio (avaliação 3). Como ela não apresentava alterações (inchaço, rubor, dor e calor) na glândula mamária afetada, não foi medicada com antibióticos específicos para mastite, apenas continuou a ingerir os medicamentos homeopáticos, entre eles o M\&P® para mastite bovina. O CMT seguinte desta vaca acusou exame negativo nesta glândula, indicando que houve um processo de cura. Almeida et al. (2005a), realizandoinoculações intramamárias experimentais com Staphylococcus aureus em seis vacas mestiças holandês x zebu, observaram que o índice de cura sem a utilização de medicamentos, fossem alopáticos ou homeopáticos, somente com ordenhas múltiplas (4 ordenhas diárias) foi de $50 \%$, semelhante ao índice de cura de mastite clínica sem uso de medicamento verificado por WiLson et al. (1999), de 57\%.

Os medicamentos homeopáticos oferecidos às vacas, em especial o FATOR M\& $\mathrm{P}^{\circledR}$, podem ter contribuído para a cura da vaca com grumos no leite, já que, conforme atestam os trabalhos de AlmEIDA et al. (2005a), Almeida et al. (2005b), SAntos; Griebeler (2006), MARTins et al. (2007), BARZON et al. (2008) e TELles et al. (2008), medicamentos homeopáticos, bioterápicos ou isoterápicos são eficazes no tratamento das mastites (clínica ou subclínica). 


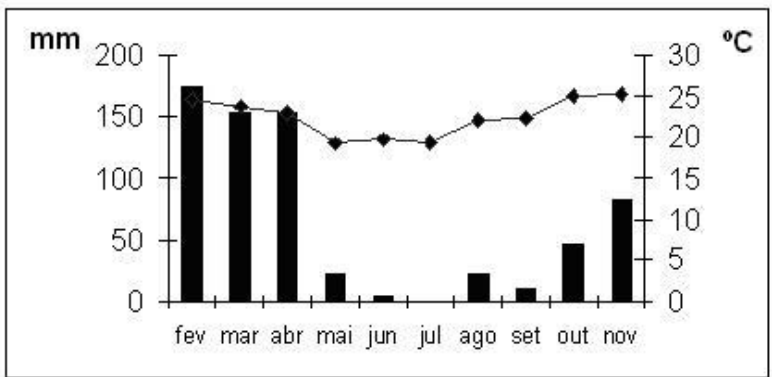

Fig. 1 - Pluviosidade $(\mathrm{mm})$ e temperatura média $\left({ }^{\circ} \mathrm{C}\right)$ nos meses em que foram feitas as avaliações em um rebanho leiteiro situado em Colina, SP.

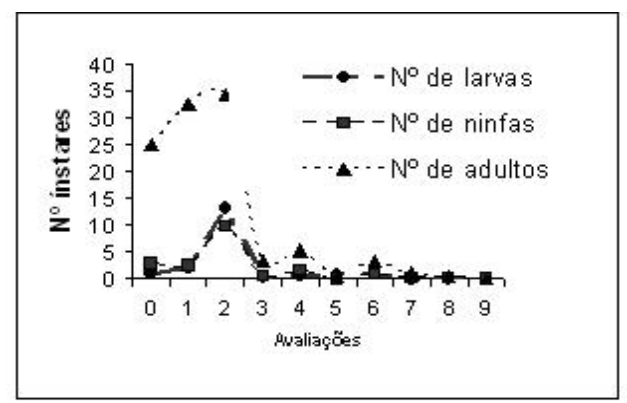

Fig. 3 - Avaliações mensais da infestação de ínstares do carrapato Riphicephalus (Boophilus) microplus, em vacas monitoradas de um rebanho que recebia medicamentos homeopáticos.



Fig. 5 - Contagem de ovos por grama de fezes (OPG) de vacas leiteiras monitoradas de um rebanho que recebia medicamentos homeopáticos.

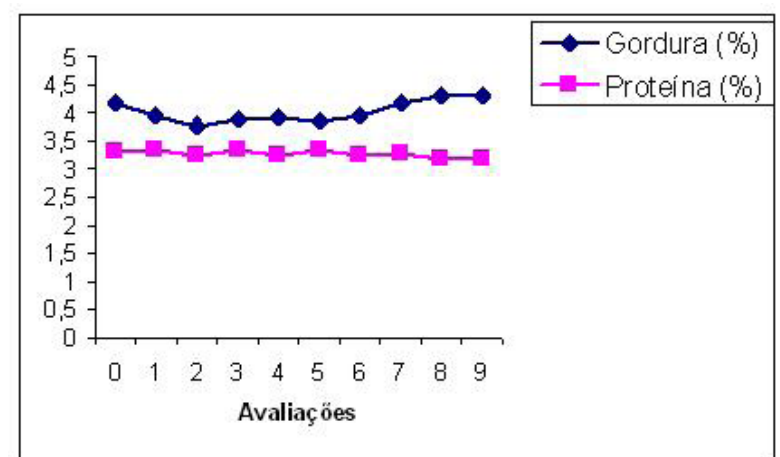

Fig. 7 - Teores médios de gordura e proteína do leite de vacas monitoradas de um rebanho que recebia medicamentos homeopáticos.

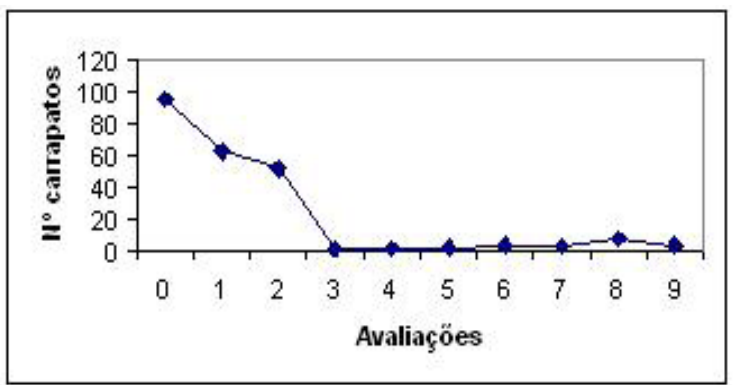

Fig. 2 - Avaliações mensais da infestação de fêmeas de Riphicephalus (Boophilus) microplus maiores que $4 \mathrm{~mm}$, em vacas monitoradas de um rebanho que recebia medicamentos homeopáticos.

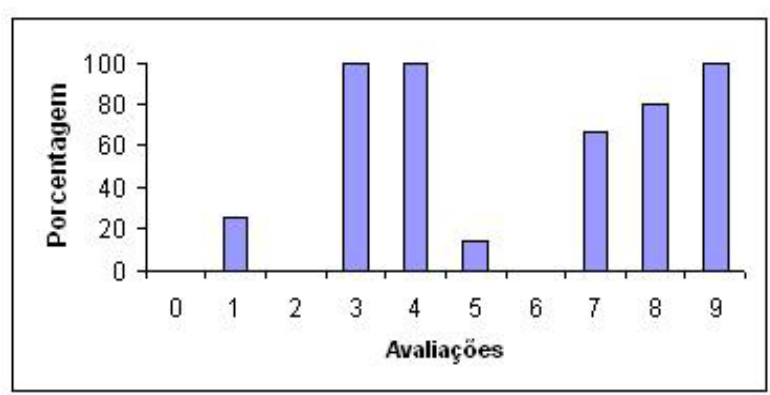

Fig. 4 - Porcentagem de vacas monitoradas com infestação superior a 20 moscas-do-chifre.

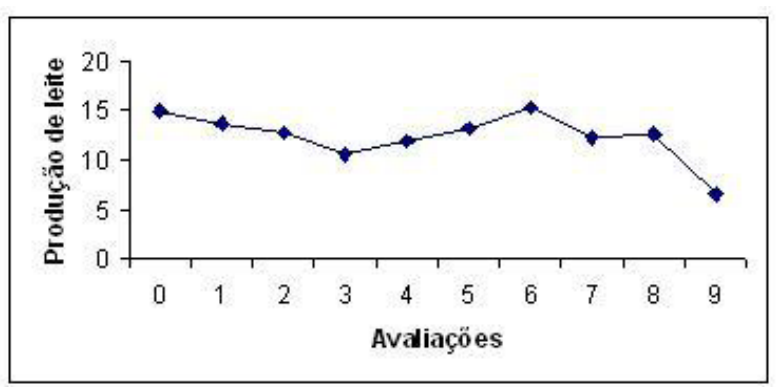

Fig. 6 - Produção média de leite (litros) de vacas monitoradas de um rebanho que recebia medicamentos homeopáticos.

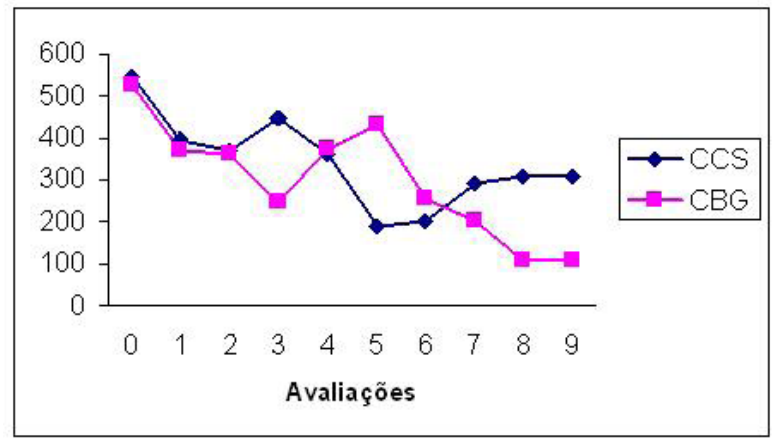

Fig. 8 - Contagens de células somáticas (CCS, mil/mL leite) e bacteriana total (CBG, $\mathrm{UFC} / \mathrm{mL}$ ) em amostras de leite do tanque de expansão de um rebanho que recebia medicamentos homeopáticos. 


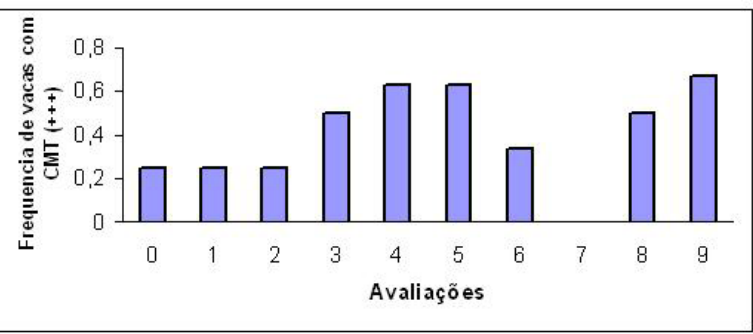

Fig. 9 - Frequencia de vacas monitoradas com pelo menos um peito com CMT $3+$ ao exame.

A produção de proteína manteve-se estável ao longo da lactação. Já a porcentagem de gordura variou mais no período, mas sempre com valores elevados (média de 4\%) (Fig. 7).

A contagem de células somáticas e contagem becteriana global, medidas em amostras do leite do rebanho, tiveram curvas descendentes (Fig. 8): a CCSiniciou com 546 mil células somáticas, chegando a um mínimo de 189 mil na quinta avaliação, e se estabilizou em cerca de 300 ao final da lactação; e a contagem bacteriana global iniciou com 526 mil UFC (unidades formadoras de colônia) / $\mathrm{mL}$ e terminou com 107 mil UFC/mL.

Verificou-se que a frequência de vacas monitoradas dentro do rebanho com pelo menos um peito positivo (3+) ao CMT aumentou nos meses de maio a julho, diminuindo em agosto e setembro, e voltando a aumentar com a proximidade do final da lactação, em novembro (Fig. 9). Os resultados sugerem que as alterações ocorridas no manejo alimentar das fêmeas no início da seca podem ter interferido na maior frequência observada de animais positivos $(3+)$ ao CMT. No final da lactação, há aumento fisiológico das células somáticas, pois, nessa fase, a CCS aumenta porque há concentração das células somáticas em função da redução fisiológica do volume de leite produzido (BUENo et al., 2005), sem esse aumento estar, necessariamente, relacionado à infecção na glândula mamária, já que a contagem de bactérias globais no tanque de expansão decresceu ao longo do período de lactação das vacas do rebanho (Fig. 8).

Arenales (2001) reportou resultados da CCS em rebanho no Estado de São Paulo, no qual houve redução após o uso do FATOR M\& ${ }^{\circledR}$ no rebanho. Em outro rebanho, houve diminuição nas aplicações de produtos químicos para o controle da mosca-dochifre, carrapato-do-boi, berne e verminose após o uso do FATOR $\mathrm{C} \& \mathrm{MC}^{\circledR}$, além do número de moscas domésticas.

MANGIERI JÚNIOR et al. (2007) não observaram diferença significativa na CCS entre vacas com CMT 2+ e 3+ que recebiam ou não o medicamento homeopático Phytolaca decandra $\mathrm{CH} 6$, mas houve aumento significativo $(\mathrm{P}<0,05)$ de $2,5 \mathrm{~kg}$ de leite/

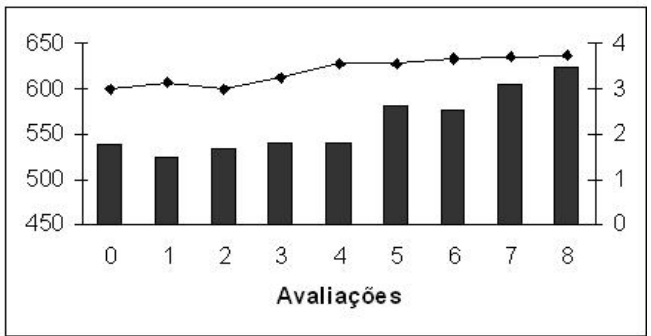

Fig. 10 - Variação no peso vivo (colunas) e condição corporal (linha) de vacas monitoradas durante a lactação em um rebanho que recebia medicamentos homeopáticos.

dia, em média, nas vacas que consumiram o medicamento homeopático.

\section{Variação no peso vivo e condição corporal}

As vacas ganharam peso e condição corporal no decorrer da lactação (Fig. 10), como esperado em um rebanho leiteiro bem manejado.

PINHEIRO et al. (2009) observaram que novilhos neloree mestiços $1 / 2$ nelore $x$ red angus que receberam FATOR C\&MC ${ }^{\circledR}$ no sal mineral tiveram menor peso final $(P<0,05)$ em relação àqueles que receberam medicação alopática para o controle de parasitos.

Durante onze meses, MitiDiero (2002) comparou vacas holandesas semiestabuladas que receberam tratamentos homeopáticos, bioterápicos e fitoterapia (T1), e tratamentos convencionais (T2). Não houve diferença significativa entre os tratamentos nas médias de produção de leite, observando-se médias de $20,15 \mathrm{~kg} /$ dia para T1 e 20,35 kg/dia para T2. Em relação à contagem de células somáticas (CCS), T1 apresentou média de 779.067 células/mL e T2 de 463.567 células/ $\mathrm{mL}(\mathrm{P}=0,07)$. Igualmente, não foi observada diferença significativa entre os tratamentos na infestação por ectoparasitas (contagem do número de teleóginas, mosca-do-chifre e berne) ou endoparasitas (OPG); tampouco em relação ao escore de condição corporal. A autora conclui que o controle sanitário de um rebanho de alta produção pode ser feito por meio de medicamentos homeopáticos, bioterapia e fitoterapia em substituição aos medicamentos alopáticos, com redução de custos de produção sem, com isso, comprometer o desempenho produtivo e sem os riscos de contaminação do leite por resíduos, constituindo-se, assim, em opção viável para a bovinocultura leiteira.

HONORATO et al. (2007) observaram a adoção da homeopatia por agricultores familiares de Antonio Prado e Ipê, RS, na criação de bovinos leiteiros, e chegaram à conclusão que a escassez de informações sobre a eficácia dos medicamentos homeopáticos contribuiu para que vários não adotassem essa terapêutica, apesar de os rebanhos tratados com medicamentos homeopáticos terem apresentado condições 
de saúde (escore corporal, aspecto da pelageme teste de mastite clínica e subclínica - CMT) comparáveis aos rebanhos tratados convencionalmente.

\section{CONCLUSÕES}

Durante o período experimental, todas as vacas do rebanho, as que estavam sendo observadas e as outras companheiras de rebanho, não foram submetidas a nenhum tratamento alopático (convencional). Os resultados obtidos demonstraram que, combom manejo nutricional e uso diário de produtos homeopáticos, é possível produzir leite de qualidade, em um sistema de produção leiteira com gado mestiço europeu $x$ zebu, sem uso de produtos químicos para controle de parasitas ou mastite. Experimento semelhante deve ser realizado comparando-se animais que recebem produtos homeopáticos com um grupo controle, não submetido ao tratamento homeopático.

\section{REFERÊNCIAS}

ALMEIDA, L.A.B.; BRITO, M.A.V.P.; BRITO, J.R.F.; PIRES, M.F.Á.; BENITES, N.R. Tratamento de mastite clínica experimental por meio de ordenhas múltiplas em vacas leiteiras inoculadas com Staphylococcus aureus. Arquivos do Instituto Biológico, São Paulo, v.72, n.1, p. 1-6, 2005a. Disponível em: <http:/ / www.biologico.sp.gov. br/docs/arq/V72_1/almeida.PDF>. Acesso: 7 nov. 2009.

ALMEIDA, A.C.; SOARES, T.M.P.; SILVA, D.B.; SILVEIRA, A.L.; FIORINI, J.E.; FONSECA, Y.M. Eficácia de tratamento homeopático no controle da mastite subclínica em bovinos. Veterinária Notícias, v.11, n.2, p.53-59, 2005b.

ARENALES, M.C. Estratégias de conversão para sistemas de produção de leite orgânico: homeopatia. In: FERNANDES, E. N.; BRESSAN, M.; VILELA, D. (Ed.). Produção orgânica de leite no Brasil. Juiz de Fora: Embrapa Gado de Leite, 2001. p.39-47.

ARENALES, M.C.; MORAES, A.; MORAES, F. Evaluation of the use of homeopathic products for the control of parasites and weight in Indian cattle (nelore), in Brazil. In: WORLD BUIATRICS CONGRESS, 24., 2006, Nice. Anais. Nice: European College of Bovine Health Management Science, 2006.

BARROS, A. T. M. Situação da resistência da Haematobia irritans no Brasil. Revista Brasileira de Parasitologia Vetetrinária, v.13, p.109-110, 2004. Suplemento 1. Trabalho apresentado no CONGRESSO BRASILEIRO DE PARASITOLOGIA VETERINÁRIA, 13.; SIMPÓSIO LATINO-AMERICANO DE RICKETIOSES, 1., 2004, Ouro Preto. Disponível em: <www.rbpv.ufrrj. br/documentos/13supl.12004/pe13s1109_110.pdf>. Acesso: 13 nov. 2009.
BARZON, C.D.; MEDEIROS, F.; MORAES, R.E.; SILVA, L.C.M.; MASSAMBANI, C.; TAKEMURA, O.S.; GAZIM, Z.C. Preliminary study of homeopathic treatment of subclinical mastitis evaluated through somatic cells count and California mastitis test. International Journal of High Dilution Research, v.7, n.24, p.147-151, 2008.

BERTOLLO, V.L. A adoção da produção mais limpa pelos agricultores familiares produtores de leite no município de Erval Grande, RS. 2002. Dissertação (Mestrado) - Universidade Regional Integrada do Alto Uruguai e das Missões, Erechim, RS, 2002. Disponível em: <www. portalga.ea.ufrgs.Br/acervo/agro_dis_01.pdf $>$. Acesso em: 7 nov. 2009.

BIANCHIN, I.; CATTO, J.B. Epidemiologia e alternativas de controle de helmintos em bovinos de corte na região central do Brasil. In: CONGRESSO BRASILEIRO DE PARASITOLOGIA VETERINÁRIA, 15., 2008, Curitiba. Anais. Curitiba: Colégio Brasileiro de Parasitologia Veterinária, 2008 (CD-ROM).

BRASIL. Ministério da Agricultura, Pecuária e Abastecimento. Instrução Normativa $n^{\circ} 51$, de 18 de setembro de 2002. Disponível em: <http:/ / www.extranet.agricultura.gov.br/sislegis-consulta/consultarLegislacao.do $>$. Acesso em: 20 fev. 2010.

BUENO, V.F.F.; MESQUITA, A.J.; NICOLAU, E.S.; OLIVEIRA, A.N.; OLIVEIRA, J.P.; NEVES, R.B.S.; MANSUR, J.R.G.; THOMAZ, LW. Contagem celular somática: relação com a composição centesimal do leite e período do ano no Estado de Goiás. Ciência Rural, v.35, n.4, p.848-854, 2005.

FARMACOPÉIA HOMEOPÁTICA BRASILEIRA. Métodos Gerais. 2.ed. São Paulo: Atheneu, 1997.

FURLONG, J.; MARTINS, J.R.; PRATA, M.C.A. O carrapato dos bovinos e a resistência: temos o que comemorar? A Hora Veterinária, v.27, n.159, 2007.

HONORATO, L.A. A interação humano-animal e o uso de homeopatia em bovinos de leite. 2006, $120 \mathrm{f}$. Dissertação (Mestrado em Agroecossistemas) - Universidade Federal de Santa Catarina, Centro de Ciências Agrárias, Florianópolis, 2006.

HONORATO, L.A.; HÖTZEL, M.J.; MACHADO FILHO, L.C.P.; KARAN, K.F. A adoção da homeopatia por agricultores familiares na criação de bovinos leiteiros. International Journal of High Dilution Research, v.6, n.20, p.22-26, 2007. Disponível em: <http://www.feg. unesp.br/ ojs/index.php/ijhdr/article/view/24/17>. Acesso em: 7 nov. 2009.

LEMOS, A.M.; TEODORO, R.L.; OLIVIERIA, G.P.; MADALENA, F. E. Comparative performance os six Holstein-Fiesian x Guzerá grades in Brazil. Animal Production, v.41, n.2, p.187-191, 1985. 
MAGALHÃES NETO, M.A.; BENEDETTI, E.;

CABRAL, D.D. Homeopatia no controle de carrapatos em bovinos leiteiros. Disponível em: <http://www.propp. ufu.br/revistaeletronica/edicao2005_2/e/homeopatia. pdf>. Acesso em: 7 nov. 2009.

MANGIERI JÚNIOR, R.; SOUTO, L. I. M.; MELVILLE, P. A.; BENITES, N. R. Avaliação de tratamento homeopático na mastite bovina subclínica. Veterinária e Zootecnia, v.14, n.1, p.91-99, 2007. Disponível em: <http://www.fmvz.unesp.br/revista/volumes/vol14/ Revista\%20v14n01_2007_91_99.pdf >. Acesso em: 7 nov. 2009.

MARTINS, C.R.; VIEIRA, E.C.; GAZIM, Z.C.; MASSAMBANI, C. Tratamento de mastite subclínica por meio de suplementação mineral homeopática da dieta de vacas leiteiras em lactação - estudo de caso. International Journal of High Dilution Research, v.6, n.19, p.16-19, 2007. Disponível em: <http://www.feg.unesp. br/ ojs/index.php/ijhdr/article/view/41/35>. Acesso em: 7 nov. 2009.

MENDONÇA, A. Tratamento homeopático na produção de leite e o cooperativismo de verdade. In: FERNANDES, E. N.; BREssan, M.; Vilela, D. (Ed.). Produção orgânica de leite no Brasil. Juiz de Fora: Embrapa Gado de Leite, 2001. p.49-58.

MITIDIERO, A. M. A. Potencial do uso de homeopatia, bioterápicos e fitoterapia como opção na bovinocultura leiteira, avaliação dos aspectos sanitários e de produção. 2002. Dissertação (Mestrado) - PGAGR, CCA-UFSC, Florianópolis, 2002. Disponível em: <http:/ /www.tede.ufsc.br/ teses/PAGR0079.pdf>. Acesso em: 7 nov. 2009.

OLIVEIRA, G.P.; ALENCAR, M.M. Resistência de bovinos de seis graus de sangue Holandês-Guzerá ao carrapato (Boophilus microplus) e ao berne (Dermatobia hominis). Arquivo Brasileiro de Medicina Veterinária e Zootecnia, v.42, n.2, p.127-135, 1990.

PINHEIRO, R. M. K.; SILVA, T. J. P.; VIANA, J. H. M. Influência do grupo genético, condição sexual e tratamento antiparasitário nas medidas de área de olho do lombo e espessura de gordura in vivo e na carcaça de bovinos de corte. Arquivo Brasileiro de Medicina Veterinária e Zootecnia, v.61, n.3, p.676-681, 2009.

SANTOS, J.S.; GRIEBELER, S.A. Tratamento homeopático da mastite do gado leiteiro. International Journal of High Dilution Research, v.5, n.14, p.9-11, 2006. Disponível em: <http://www.feg.unesp.br/ ojs/index.php/ijhdr/ article/view/151/154>. Acesso em: 7 nov. 2009.

SANTOS, A.L.; LIMA, M.L.P.; BERCHIELLI, T.T.; LEME, P.R.; MALHEIROS, E.B.; NOGUEIRA, J.R.; PINHEIRO, M.G.; LIMA, N.P.; SIMILI, F.F. Efeito do dia de ocupação sobre a produção leiteira de vacas mestiças na forragem em pastejo rotacionado de forrageiras tropicais. Revista Brasileira de Zootecnia, v.34, n.3, p.10511059, 2005.
SCHALM, O.W.; NOORLANDER, D.O. Experiments and observations leading to development of the California Mastitis Test. Journal of American Veterinary Medical Association, v.130, n.5, p.199-207, 1957.

SIGNORETTI, R.D.; VERÍSSIMO, C.J.; SOUZA, F.H.M.; GARCIA, T.S.; OLIVEIRA, E.M.; SOUZA, K.G.; MOURÃO, G.M. Desempenho e infestação por parasitos em machos leiteiros suplementados com sal proteinado com ou sem os medicamentos homeopáticos. Revista Brasileira de Parasitologia Veterinária, v.17, p.40-44, 2008. Suplemento 1.

SILVA, A.M.C.P.; SCHWARTZ, F.F.; CARDOSO, M.V., CÉSAR, A.T.; SOLLERO, P.A. Uso de bioterápico de Mycoplasma spp. em rebanho bovino leiteiro. International Journal of High Dilution Research, v.4, n.13, p.43-47, 2005.

SILVA, N.L.; MOLETTA, J.L.; MINHO, A.P.; FILIPPSEN, L.F. Use of biotherapic in the control of natural infestation by Boophilus microplus: pilot study. International Journal of High Dilution Research, v.7, n.22, p.35-37, 2008.

TELLES, D.Z.; SILVESTRE, L.; GOMES, O.P. Avaliação microbiológica de amostras de leite oriundo de mamites sub-clínicas antes e após tratamento homeopático. In: CONGRESSO BRASILEIRO DE MEDICINA VETERINÁRIA, 35., 2008, Gramado. Anais. Gramado: Sociedade Brasileira de Medicina Veterinária, 2008, Disponível em: <http://www.sovergs.com.br/conbravet2008/anais/ cd/resumos/R1194-1.pdf, Acesso em: 7 nov. 2009.

UENO, H.; GONÇALVES, P.C. Manual para diagnóstico das helmintoses de ruminantes. 4.ed. Tokio: Japan International Cooperation, 1998.

VERISSIMO, C.J. Utilização do nosódio Carrapatinum em bovinos sensíveis ao carrapato Boophilus microplus (Canestrini). Pesquisa Homeopática, v.5, n.1, p.21-25, 1988.

VERISSIMO, C.J. Prejuízos causados pelo carrapato Boophilus microplus. Zootecnia, v.31, n.3/4, p.97-106, 1993.

VERISSIMO, C.J. Controle biológico do carrapato Boophilus microplus. In: AMBROSANO, E. (Org.). Agricultura ecológica. Guaíba: Livraria e Editora Agropecuária, 1999. p.205-215.

VERÍSSIMO, C.J. Homeopatia e controle da verminose. In: VERÍSSIMO, C.J. (Coord.). Alternativas de controle da verminose em pequenos ruminantes. Nova Odessa: Instituto de Zootecnia, 2008. p.56-62.

VERÍSSIMO, C.J.; MACHADO, S.G. Fase de vida livre do ciclo evolutivo do carrapato Boophilus microplus. Zootecnia, v.33, n.2, p.41-53, 1995.

VERÍSSIMO, C.J.; OLIVEIRA, A.A.D. Método simplificado de contagem para avaliar a resistência de bovinos ao carrapato Boophilus microplus. Boletim da Indústria Animal, v.51, n.2, p.169-173, 1994. 
VERISSIMO, C.J.; SILVA, R.G.; OLIVEIRA, A.A.D.; RIBEIRO, W.R.; ROCHA, U.F. Resistência e suscetibiliade de bovinos leiteiros mestiços ao carrapato Boophilus microplus. Boletim da Indústria Animal, v.54, n.2, p 1-10, 1997a.

VERISSIMO, C.J.; SILVA, R.G.; OLIVEIRA, A.A.D.; RIBEIRO, W. R.; ROCHA, U.F. Contagens de ínstares do carrapato Boophilus microplus em bovinos mestiços. Boletim da Indústria Animal, v.54, n.2, p.19-24, 1997b.

VERISSIMO, C.J.; OTSUK, I.P.; DEODATO, A.P.; LARA, M.A.C.; BECHARA, G.H. Infestação por carrapatos Boophilus microplus (Acari: Ixodidae) em vacas das raças Gir, Holandesa e mestiça sob pastejo. Arquivos do Instituto Biológico, São Paulo, v.69, p.87-89, 2002. Suplemento.

WILSON, D.J.; GONZALEZ, R.N.; CASE, K.L.; GARRISON, L.L.; GRÖHN, Y.T. Comparison of seven antibiotic treatments with no treatment for bacteriological efficacy against bovine mastitis pathogens. Journal of Dairy Science, v.82, n.8, p.1664-1670, 1999.

Recebido em 24/11/09

Aceito em 2/12/10 